\begin{tabular}{l}
\hline \hline GEOSPORT FOR SOCIETY \\
$\begin{array}{c}\text { GEOSPORT } \\
\text { SOCIETY }\end{array}$ \\
Scientific Journal founded in 2014 under aegis of University of Oradea (Romania), \\
University of Debrecen (Hungary), University of Gdánsk (Poland) \\
ISSN 2393-1353 \\
Edited by Oradea University Press \\
1, University Street, 410087, Oradea, Romania \\
Journal homepage: $h$ ttp://geosport.uoradea.ro/geosport.html
\end{tabular}

\title{
What Do Physiotherapists Know About Techno-Therapy?
}

\section{Esra Dogru HUZMELI ${ }^{1 *}$, Ozden GOKCEK ${ }^{1}$, Sabiha BEZGIN ${ }^{2}$, Yagmur CAM 1 , Hasan HALLACELI ${ }^{3}$, Senem URFALI ${ }^{4}$, Murat GUNTEL ${ }^{5}$, Irem KARANKI ${ }^{6}$}

1. Hatay Mustafa Kemal University, Health Science Faculty, Physiotherapy and Rehabilitation Department, Hatay, Turkey, e-mail: esradogru001@hotmail.com / ozdencanbay@hotmail.com/yyagmurcam@gmail.com

2. Kırıkkale University, Health Science Faculty, Physiotherapy and Rehabilitation Department, Kırıkkale, Turkey, email: sabihasahilog@gmail.com

3. Hatay Mustafa Kemal University Tayfur Sokmen Medicine Faculty, Orthopedics and Traumatology Department, Hatay, Turkey, e-mail: hasanhallaceli@hotmail.com

4. Hatay Mustafa Kemal University, Medicine Faculty, Reanimation and Anesthesia Department, Hatay, Turkey, email: senemurfali@yahoo.com

5. Hatay Mustafa Kemal University, Tayfur Sokmen Medicine Faculty, Neurologia Department Hatay, Turkey, e-mail: muratguntel@hotmail.com

6. Halic University Health Science Faculty Physiotherapy and Rehabilitation Department, Istanbul, Turkey, e-mail: iremkaranki@halic.edu.tr

* Corresponding author

Citation: Huzmeli, E.D., Gokcek, O., Bezgin, S., Cam, Y, Hallaceli, H., Urfali, S., Guntel, M., Karanki, I. (2020). What Do Physiotherapists Know About Techno-Therapy?. Geosport for Society, 12(1), 24-30. https://doi.org/10.30892/gss.1203-055

Article history: Received: 03.01.2020; Revised: 05.02.2020; Accepted: 20.03.2020, Available online: 25.03.2020

\begin{abstract}
Aim: The aim of this study was to examine the knowledge of the physiotherapists about technotherapy, so we want to take attention on the importance of updating the physiotherapist themselves about new rehabilitation devices that the physiotherapists use and to encourage the in-service training regularly. Methods: The study group consists of 24 physiotherapists working in Hatay. The survey consisted mostly of open-ended questions. These are the questions that were asked to the physiotherapists: Q1: Do you know what is the virtual reality?, Q2: What does augmented therapy mean?, Q3: What do you know about technological equipment to help patients that have communication problems?, Q4: What do you know about wearable rehabilitation technology ?, Q5: What do you know about robotic rehabilitation ?, Q6: Do you use any technologic equipment in your treatment?, Q7: Did you have courses about technology during your university education ?. The first 5 questions' answers were assessed as "false", "true" or "do not know" and the last two questions as "yes" or "no" by an assistant professor. Results: Fourteen females, ten males aged between 22-60 years $(X+S D=29.83 \pm 8.8)$ totally 24 individuals were included in the study. Questions (Q) results are following:Q1:23 of their answers were true, 1 was false;Q2:All of them answered as do not know; Q3:1 of them answered as false, 1 of them as true and 22 of them as do not know; Q4: 1 of them answered as false, 1 of them as true and 22 of them as do not know; Q5: 18 of them answered as true, 6 of them as false; Q6: 6 of them answered as yes, 18 of them as no; Q7:5 of them answered as yes, 19 of them as no. Discussion: As a result, we learned that most of the
\end{abstract}


physiotherapists do not have sufficient knowledge about techno-therapy devices and that they have heard some applications for the first time during the survey. We concluded that physiotherapists need to follow up on current practice and devices and that universities can assume the role of mentors and organize instruction at regular intervals to help physiotherapists to update their knowledge about new technologies.

Keywords: physiotherapist, techno-therapy, rehabilitation technology

\section{Introduction}

Techno-therapy is a movement in which health researchers, clinicians, technologists, and entrepreneurs can collaborate on the establishment of a new approach to therapy. This approach has been developed according to the therapist and patient relationship and major innovations have been recorded in recent years. Due to ongoing changes and innovations in the nature of the professional work, physiotherapists need to improve themselves on evidence-based practices continually (Schultheis and Rizzo, 2001; Breines, 2002 ; Sherman et al., 2018).

It is stated in the studies that techno-therapy methods based on information and communication technologies such as tele-physiotherapy (Howard, 2017), which can make to provide management of the rehabilitation process easier and, are effective and usable in many disease groups (Wiederhold et al., 1998; Bohil et al., 2011; Laufer et al., 2011). Robotic techno-therapy methods, which increase the reproducibility, productivity, and efficiency of movement, can significantly assist the therapist in the process of administering the treatment (Poli et al, 2013; Hesse, 2003; Diaz et al., 2011), but techno-therapy equipment is rarely used in small cities and in small rehabilitation centers. Therefore, a physiotherapist may be unaware of technotherapy and patients may not find the chance of having the benefit of this equipment. This study aimed to examine the knowledge of the physiotherapists about technotherapy that work in Hatay, Turkey, so we want to take attention on the importance of updating the physiotherapists themselves about the rehabilitation technology, and to encourage the in-service training regularly.

\section{Methods}

The research is a qualitative study that aimed to examine the knowledge level of individuals working as physiotherapists about technological devices used in the field of physiotherapy (Yildirim and Simsek, 2008). The study consists of 24 physiotherapists working in Hatay. 30 physiotherapists that work in rehabilitation centers for pediatric, public hospitals, and private hospitals were invited to participate the study. 24 physiotherapists accepted the interview (Yildirim and Simsek, 2008). We questioned their institution, working duration, and working area.

In this study, a structured interview technique was used as a data collection method. This approach consists of a series of carefully written and ordered questions 
and each interviewee is asked in the same manner and order. Before the interview questions were prepared, a national and international literature review related to the research topic was conducted. After the subject was designed, the items that were thought to be included in the form were determined. The survey consisted mostly of open-ended questions. These are the questions that were asked to the physiotherapists: Q1: Do you know what is the virtual reality?, Q2: What does augmented therapy mean?, Q3: What do you know about technological equipment to help patients that have communication problems?, Q4: What do you know about wearable rehabilitation technology?, Q5: What do you know about robotic rehabilitation ?, Q6: Do you use any technologic equipment in your treatment ?, Q7: Did you have courses about technology during your university education ?. The first 5 questions' answers were assessed as "false", "true" or "do not know" and the last two questions as "yes" or "no" by an assistant professor.

Three faculty members, three physiotherapists, and three physiotherapy students were interviewed in order to evaluate these items in terms of purpose, meaning, and scope. After these steps, the form was finalized using the information obtained and the interview questions were directed to the participants in the research. Data related to the study were collected from the determined physiotherapists by interviewing in 2018. Information about the research was given during the interview. In the research, we dealt to provide an appropriate interaction environment, in which participants could feel comfortable and confident and express their views sincerely during the interview. In addition, it is stated that individuals may not write names on the paper they write in a comfortable and uncensored manner.

\section{Results}

Fourteen females, ten males aged between 22-60 years $(X+S D=29.83 \pm 8.8)$ totally 24 individuals were included in the study. Their occupation duration's mean was 6.58 \pm 7.67 years (table 1 ).

Table 1. Descriptive results of the physiotherapists

\begin{tabular}{|c|c|c|c|}
\hline & & \multicolumn{2}{|c|}{$\begin{array}{c}X \pm S D \\
(n=24)\end{array}$} \\
\hline & Age (Years) & \multicolumn{2}{|c|}{$30.40 \pm 8.99$} \\
\hline \multicolumn{2}{|c|}{ Working Duration (Years) } & \multicolumn{2}{|c|}{$7.09 \pm 7.73$} \\
\hline & & $\mathbf{n}$ & $\%$ \\
\hline \multirow[t]{3}{*}{ Institution } & Rehabilitation Center for Children & 14 & 58,3 \\
\hline & Private Hospital & 4 & 16,7 \\
\hline & Public Hospital & 6 & 25 \\
\hline \multirow{2}{*}{$\begin{array}{c}\text { Working } \\
\text { Area }\end{array}$} & Pediatric Physiotherapy & 14 & 58,3 \\
\hline & General Physiotherapy & 10 & 41,7 \\
\hline
\end{tabular}


Questions (Q) results are following: Q1: 23 of their answers were true, 1 was false; Q2: All of them answered as do not know; Q3: 1 of them answered as false, 1 of them as true and 22 of them as do not know; Q4: 1 of them answered as false, 1 of them as true and 22 of them as do not know; Q5: 18 of them answered as true, 6 of them as false; Q6: 6 of them answered as yes, 18 of them as no; Q7: 5 of them answered as yes, 19 of them as no (table 2).

Table 2. Results of the physiotherapist's knowledge about techno-therapy

\begin{tabular}{|c|c|c|c|c|c|c|}
\hline \multirow[t]{2}{*}{ QUESTIONS } & \multicolumn{2}{|c|}{ True } & \multicolumn{2}{|c|}{ False } & \multicolumn{2}{|c|}{ Do not know } \\
\hline & (n) & $\%$ & (n) & $\%$ & (n) & $\%$ \\
\hline $\begin{array}{l}\text { 1. Do you know what is the virtual } \\
\text { reality? }\end{array}$ & 23 & 95.83 & 1 & 4.16 & 0 & 0 \\
\hline 2. What does augmented therapy mean? & 0 & 0 & 0 & 0 & 24 & 100 \\
\hline $\begin{array}{c}\text { 3. What do you know about } \\
\text { technological equipment to help } \\
\text { patients that have communication } \\
\text { nroblems? }\end{array}$ & 1 & 4.16 & 1 & 4.16 & 22 & 91.52 \\
\hline $\begin{array}{l}\text { 4. What do you know about wearable } \\
\text { rehabilitation technology? }\end{array}$ & 1 & 4.16 & 1 & 4.16 & 22 & 91.52 \\
\hline \multirow[t]{3}{*}{$\begin{array}{l}\text { 5. What do you know about robotic } \\
\text { rehabilitation? }\end{array}$} & 18 & 75.04 & 6 & 24.96 & 0 & 0 \\
\hline & \multicolumn{3}{|c|}{ Yes } & \multicolumn{3}{|c|}{ No } \\
\hline & (n) & \multicolumn{2}{|c|}{$\%$} & \multicolumn{2}{|c|}{ (n) } & $\%$ \\
\hline $\begin{array}{l}\text { 6. Do you use any technologic } \\
\text { equipment during your treatment of the } \\
\text { patient? }\end{array}$ & 6 & \multicolumn{2}{|c|}{24.96} & \multicolumn{2}{|c|}{18} & 75.04 \\
\hline $\begin{array}{c}\text { 7. Did you have courses about } \\
\text { technology during your university } \\
\text { education? }\end{array}$ & 5 & \multicolumn{2}{|c|}{20.8} & \multicolumn{2}{|c|}{19} & 79.2 \\
\hline
\end{tabular}

\section{Discussion}

This study was planned to evaluate the level of knowledge of physiotherapists about the technological devices and applications used in the rehabilitation field who are actively working in different units in Hatay and to determine the extent to which they update themselves. As a result, we learned that most of the physiotherapists do not have sufficient knowledge about techno-therapy devices and that they have heard some applications for the first time during the survey. We concluded that physiotherapists need to follow up on current practice and devices and that universities can assume the role of mentors and organize instruction at regular intervals to help physiotherapists to update their knowledge about new technologies. 
Technology is developing day by day. We see the effects of this rapidly developing technology on our lives in many areas. With the rapid advancement of technology, it has provided great opportunities for evaluating, monitoring, treating and researching patients in the field of physiotherapy and rehabilitation. Virtual reality applications, robotic rehabilitation, motion sensor evaluation devices, which have attracted attention with their use in many areas especially in recent years, are also frequently used in the field of physiotherapy and rehabilitation (Peacock and Hooper, 2007). In order not to be left behind by the developing and advancing technology, physiotherapists need to know for what purposes, how and in which disease states these devices can be used. This information can be provided in the basic education curricula or can be provided by the continuation of the education process within personal interests (Lum et al., 2002).

As a result of our study, it was concluded that techno-therapy applications in the field of physiotherapy and rehabilitation, in general, are not known by the physiotherapists and are not included in the treatment process. Physiotherapists except virtual reality applications; augmented therapy, wearable rehabilitation technologies and technological applications for communication problems do not know and do not use in the treatment. So it is an important deficiency for the patients. There are many different problem-solving devices, but the patients could not attain that device, because the health professionals do not know those devices and do not guide them.

Apart from physiotherapy and rehabilitation, virtual reality applications are now encountered in many areas from entertainment to education in daily life (Timmermans, 2009). Unlike other techno-therapy applications, this is thought to be one of the reasons why it is more familiar to physiotherapists. Apart from this, virtual reality applications have a more widespread usage area in the rehabilitation process which is relatively easier to access than other methods (Kittipanya-ngam et al., 2009). Thanks to inexpensive equipment, many clinics have this techno-therapy (Zhou et al., 2005; Zheng, 2005). For physiotherapists working with children, having a safe and entertaining approach increases its use in treatment (Rusell, 2011). Thanks to these advantages, it is an expected result that physiotherapists know to a greater extent about virtual reality.

Robotic rehabilitation practices seem to be rapidly embarking on rehabilitation programs, particularly in the last decade. It is used in many different disease groups due to its positive aspects such as the timing of movement, coordination and supporting the motor learning process (Tejima, 2011). Rapid advances in technology have led to the development of different robotic systems. Although it is not easy to have information about all systems in this wide range, knowing the areas of use, in general, provides ease of use for patients and physiotherapists in rehabilitation. 
However, the cost of robotic systems reduces their availability (Huang and Krakauer, 2009). As a natural consequence of this, recognition is diminishing. Although the cost of the systems constitutes an obstacle to its spreading, it can be ensured that information can be provided with the education that can be taken after the license or post-license. Physiotherapists, who know as a result of the education, are expected to get a benefit from robotic rehabilitation in their workplaces and this will facilitate their spreading.

When the physiotherapists were asked whether they took courses related to techno-therapy applications at the undergraduate level; it was concluded that this training was not taken at the undergraduate level. This result shows that the source of the lack of information and the limitation in use is the inadequacy of undergraduate education.

As a result of our study, it was concluded that physiotherapists do not have knowledge about techno-therapy applications sufficiently and do not use these technological tools in the treatment. Since it is not known about the technological devices, it is considered that because its purpose, place, and importance in treatment are unknown it cannot be used. It is thought that with a course to be given at the undergraduate level, awareness can be created in physiotherapists and it is possible to create working areas on the subject after the undergraduate education. Also, we concluded that there should be education for graduate physiotherapists to help them to update themselves about new methods that both the patients and national economy get a benefit, and the universities should accept it as a mission to provide education for graduated health profession about new devices and new treatment methods.

\section{References}

Bohil, C. J., Alicea, B., \& Biocca, F. A. (2011). Virtual reality in neuroscience research and therapy. Nature reviews neuroscience, 12(12), 752-762.

Breines, E. B. (2002). Occupational therapy education in a technological world. American Journal of Occupational Therapy, 56(4), 467-469.

Díaz, I., Gil, J. J., \& Sánchez, E. (2011). Lower-limb robotic rehabilitation: literature review and challenges. Journal of Robotics, 2011.

Hesse, S., Schmidt, H., Werner, C., \& Bardeleben, A. (2003). Upper and lower extremity robotic devices for rehabilitation and for studying motor control. Current opinion in neurology, 16(6), 705-710.

Howard, M. C. (2017). A meta-analysis and systematic literature review of virtual reality rehabilitation programs. Computers in Human Behavior, 70, 317-327.

Huang, V. S., \& Krakauer, J. W. (2009). Robotic neurorehabilitation: a computational motor learning perspective. Journal of neuroengineering and rehabilitation, 6(1), 5.

Kittipanya-ngam, P., Yu, X., \& Eng, H. L. (2009). Computer vision technologies for monitoring system in tele-physiotherapy. In Proceedings of the 3rd International Convention on Rehabilitation Engineering \& Assistive Technology (pp. 1-4).

Laufer, Y., \& Weiss, P. T. L. (2011). Virtual reality in the assessment and treatment of children with motor impairment: a systematic review. Journal of Physical Therapy Education, 25(1), 59-71. 
Lum, P., Reinkensmeyer, D., Mahoney, R., Rymer, W. Z., \& Burgar, C. (2002). Robotic devices for movement therapy after stroke: current status and challenges to clinical acceptance. Topics in stroke rehabilitation, 8(4), 40-53.

Peacock, S., \& Hooper, J. (2007). E-learning in physiotherapy education. Physiotherapy, 93(3), 218-228.

Poli, P., Morone, G., Rosati, G., \& Masiero, S. (2013). Robotic technologies and rehabilitation: new tools for stroke patients' therapy. BioMed Research International, 2013.

Russell, T. (2011). Tele-rehabilitation as successful as out-patient physiotherapy post total knee replacement. Journal of Bone and Joint Surgery, 93(2), 113-120.

Schultheis, M. T., \& Rizzo, A. A. (2001). The application of virtual reality technology in rehabilitation. Rehabilitation psychology, 46(3), 296-311.

Sherman, W. R., \& Craig, A. B. (2018). Understanding virtual reality: Interface, application, and design. Morgan Kaufmann.

Tejima, N. (2001). Rehabilitation robotics: a review. Advanced Robotics, 14(7), 551-564.

Timmermans, A. A., Seelen, H. A., Willmann, R. D., \& Kingma, H. (2009). Technology-assisted training of arm-hand skills in stroke: concepts on reacquisition of motor control and therapist guidelines for rehabilitation technology design. Journal of neuroengineering and rehabilitation, 6(1), 1.

Wiederhold, B. K., \& Wiederhold, M. D. (1998). A review of virtual reality as a psychotherapeutic tool. CyberPsychology \& Behavior, 1(1), 45-52.

Yildirim, A., \& Simsek, H. (2008). Sosyal bilimlerde nitel arastirma yontemleri. Ankara: Seckin.

Zheng, H., Davies, R. J., \& Black, N. D. (2005, June). Web-based monitoring system for home-based rehabilitation with stroke patients. In 18th IEEE Symposium on Computer-Based Medical Systems (CBMS'05) (pp. 419-424). IEEE.

Zhou, H., Hu, H., \& Harris, N. D. (2006, March). Wearable inertial sensors for arm motion tracking in home-based rehabilitation. In IAS (pp. 930-937). 